\title{
Responsible alcohol service: lessons from evaluations of server training and policing initiatives
}

\section{TIM STOCKWELL}

\author{
National Drug Research Institute, Perth, Australia
}

\begin{abstract}
Responsible alcohol service programmes have evolved in many countries alongside a general increase in the availability of alcohol and a greater focus on the prevention of alcohol-related road crashes. They also recognize the reality that a great deal of high-risk drinking and preventable harm occurs in and around licensed premises or as drinkers make their way home. Early US efficacy studies of programmes which trained managers and barstaff to limit customers' levels of intoxication and prevent drink driving showed promise. Studies of effectiveness of these programmes in the wider community, and in the absence of the enforcement of liquor laws, found little benefit. The data will be interpreted as suggesting that, in reality, skills deficits in the serving of alcohol are not a significant problem compared with the motivational issue for a commercial operation of abiding by laws that are rarely enforced and which are perceived as risking the goodwill of their best customers. Australian, UK and US experiences with liquor law enforcement by police will be discussed along with outcomes from the Australian invention of Alcohol Accords, informal agreements between police, licensees and local councils to trade responsibly. It will be concluded that the major task involved in lifting standards of service and preventing harm is to institutionalize legal and regulatory procedures which impact most on licensed premises. A number of strategies are suggested also for creating a political and social climate which supports the responsible service of alcohol and thereby supports the enactment and enforcement of appropriate liquor laws. [Stockwell T. Responsible alcohol service: lessons from evaluations of server training and policing initiatives. Drug Alcohol Rev 1001; 20:257-265]
\end{abstract}

Key words: responsible beverage service, alcohol, licensed premises, law enforcement, self-regulation, BAC, drink-driving, violence

\section{Introduction}

Like many social movements, Responsible Beverage Service (RBS) began in North America with the first published evaluations concerning programmes initiated in California [1] and Ontario [2]. These early pro- grammes had a predominant focus on the prevention of drinking and driving, mainly through training barstaff and their managers to limit levels of intoxication attained by their customers. Mainly North American

Tim Stockwell MA, MSc, PhD, Director, National Drug Research Institute, GPO Box U1987, Perth WA 6845, Australia. Correspondence to Tim Stockwell. 
research reviewed by O'Donnell [3] suggested that approximately $50 \%$ of alcohol-related crashes involve the prior consumption of alcohol on licensed premises, making them a logical focus for prevention.

Another trigger for the growth of RBS during the 1980s and 1990s was the rapid rise in civil actions brought against North American licensees on whose premises drivers were served to dangerous levels of intoxication before driving and seriously injuring a third party [4]. Some of these lawsuits involved the payment of millions of dollars to the injured parties, principally on the basis that the licensed establishment had in fact broken the law by serving a patron until they achieved a state of obvious intoxication. Liquor laws in almost all North American jurisdictions make it an offence to serve alcohol to an already intoxicated customer. Civil cases have also established a legal principle of negligence in such cases and 'vicarious liability' for the actions of customers even after they have left the premises [4]. The drafting of model 'Dram Shop' laws which clarify and codify such vicarious liability was also a direct trigger for RBS programmes since they also identified acceptable defences against legal action - principally by providing evidence that everything possible was done to prevent such incidents occurring by, for example, appropriate training of staff [5].

Legal liability for licensees has been far more limited in other English-speaking countries [6]. In Australia, for example, there is a state-run victim's compensation scheme for people injured in road crashes and hence it has not usually been necessary to resort to civil action to gain compensation, although there have been a few cases involving relatively small sums of money [4]. It is arguable that the process of deregulation of the licensed drinking environment in terms of trading hours, controls on outlet density and age of drinking in many non-US developed countries [7] has also contributed to an interest in RBS and related strategies. What other avenues are open to concerned citizens for the control of local alcoholrelated problems when there is 24-hour trading and reluctance among regulators to either refuse or cancel liquor licences? It may be useful to view the RBS movement within this framework, certainly in Australia and New Zealand, where Host Responsibility (incorporating licensed and unlicensed establishments) and mandated server training are becoming widespread: regardless of the time and place where alcohol is served, RBS seeks to ensure intoxication and hence alcohol-related harm is minimized.
This paper will consider evidence for the potential effectiveness of RBS and also various law enforcement initiatives. It will then address the more important issue of how to create a legislative, regulatory and socio-political environment within which alcohol is served and consumed with lowered risk of harm. A parallel development to RBS has been the development of policing strategies designed to limited public disorder generally and alcoholrelated violence in particular. A number of studies from around the world have documented the strong association between public violence and drinking on licensed premises (e.g. [8]). In Western Australia, Chikritzhs et al. [9] report a peak in violence in and around licensed premises at closing time which shifts when closing times alter and increase in frequency when alcohol purchases are elevated by longer trading hours. There is now a strong consensus in the literature that the association between drinking, violence and licensed premises can be attributed directly to intoxication increasing the risk of violence in a number of social situations which are already conducive to conflict and frustration $[10,11]$. The evidence for the potential benefits of police enforcement strategies to reduce public order problems as well as more informal strategies designed to facilitate self-regulation by licensees with the assistance and encouragement of police and concerned citizens will also be discussed. The range of serious problems associated with drinking on licensed premises and the range of agencies with the potential to intervene effectively demands that to be fully effective RBS needs to be conceptualized as part of a comprehensive range of local prevention and policy measures.

\section{Can RBS programmes achieve their goals?}

Early studies of RBS simply sought to establish whether such programmes could limit intoxication under optimal conditions. A classic example was the Navy Server Study conducted by Saltz [1], in which two similar US Navy social clubs participated, one as the intervention site and the other as a control. High-level support was accorded the project, the club manager in the intervention site was persuaded to introduce a number of changes to club policies and serving staff received a total of 18 hours of training, including a focus on practical skills for detecting intoxication, slowing down service and service refusal if required. Policy changes introduced 
included not serving beer in large 'pitchers', making food more available and having staff systematically monitor alcohol consumption in every area of the bar. Customers' self-reported alcohol consumption as well as direct observations of their drinking were used to estimate the proportions who would have achieved a BAC of $0.10 \%$. There was a significant reduction of this proportion in the intervention site from $33 \%$ to $15 \%$ with little change at the control site.

Russ \& Geller [12] employed a different design when evaluating the Training in Intervention Procedures by Servers of Alcohol (TIPS) programme in two fully co-operative commercial bars. Approximately half of the staff in both establishments attended and passed a 6-hour training course with similar objectives to the Navy Server Study. Research assistants posed as customers and attempted to purchase a drink every 20 minutes for 2 hours. Outcome measures were the responses of bar staff and the BACs attained by these 'pseudo-patrons'. It was found that trained staff intervened to slow or stop consumption on average 3.24 times per pseudo-patron performance compared with only 0.75 times for untrained staff. Furthermore, the BACs attained by patrons served by trained staff was significantly lower $(0.059 \%)$ than those served by untrained staff $(0.103 \%)$.

A later Canadian study conducted by Gliksman and colleagues in Thunder Bay, Ontario extended server training to four commercial establishments and used four control sites [2]. A modest but significant change in server behaviour towards RBS ideals was demonstrated in the intervention sites.

From these promising beginnings, RBS programmes progressed towards larger effectiveness involving many more sites and training of hundreds of barstaff. Sadly, the early promise of the first demonstration projects was not realised in studies reported from the United States and Western Australia.

In one of the largest studies recorded to date, McKnight [13] evaluated the impact of RBS training of 6 hours for managers and 3 hours to barstaff across 100 premises in eight US cities against 135 control establishments. A total of 1079 staff were trained. Pseudo-patrons were employed to feign signs of intoxication on entry to each establishment and recorded whether or not they were refused service-a demanding criterion. It was found that there was a small increase in other forms of RBS intervention (offering non-alcoholic alternatives, slowing service) from $14 \%$ to $27 \%$, but that outright service refusal remained very low at $5 \%$.

At the other side of the world, Lang et al. [14] reported on a smaller community-wide intervention study in the port city of Fremantle, Western Australia. Over 130 bar staff were trained in seven of the larger licensed premises which had been found to be responsible for over $70 \%$ of incidents of harm (assaults and drink-driving offences) associated with premises in that area. A neighbouring entertainment area was used as a control with seven matched establishments and no interventions. Both police personnel and a trainer selected by the local retail trade association were involved in service delivery. Managers were encouraged to develop responsible house policies covering 11 key areas (serving underage and intoxicated, safe transport home, preventing violence, providing non-alcoholic alternatives, etc.). While there were significant changes in the knowledge of responsible service issues among barstaff who attended the course and a significant reduction in the number of patrons exiting premises with BACs above 0.08 , there were no changes in rates of service refusal to 'drunk' pseudo-patrons or an increase in appropriate age-ID checking and only minimal changes overall in the implementation of responsible House Policies by participating venues. One notable exception was of a high-profile hotel (Australian term for a large bar, tavern or 'pub') which introduced a range of new policies, refused service to drunk pseudo-patrons, had no patrons exiting with BACs in excess of 0.15 and reported increased profits.

Two important conclusions can be drawn from these American and Australian experiences. The first is that when RBS training is applied at a community-wide level, the promising impact measured in the demonstration projects is diluted. The extent to which this is due to the absence of favourable selection factors in the smaller demonstration studies as opposed to shorter training is unclear. At least some of this dilution appears to be associated with a failure to whole-heartedly implement the principles of RBS. It works well where there is strong back-up from management but this cannot be guaranteed by any means on a purely voluntary basis.

Another approach to the issue of compliance with RBS principles is one of the enforcement of existing liquor laws, whether by police or civilian licensing inspectors. 


\section{A comparison of RBS and law enforcement approaches}

In many countries liquor laws include clear legal requirements that alcohol is not served to drunk or under-age people. The former of these provisions in particular (serving drunk people) is in the main hardly enforced in many jurisdictions, partly because of difficulties of defining what constitutes 'intoxication' or drunkenness and partly because of low priority accorded by police and/or licensing authorities to this issue [e.g. 15].

There have been some documented attempts to formalize the role of police in relation to RBS by having an active and explicit enforcement programme. Two classic examples will be outlined which permit a direct comparison between law enforcement and a voluntary approach involving training staff in RBS principles.

In the late 1980s Dr James McKnight, President of the National Public Services Research Institute, Maryland, USA approached police chiefs from over 100 US jurisdictions seeking expressions of interest in evaluating a law enforcement approach to responsible alcohol service. Eight expressed willingness to participate and Michigan was eventually selected as a demonstration site enabling a comparison with the results of the server training study conducted there a few years earlier. The enforcement programme involved plain-clothes police visiting premises in order to check for intoxicated customers and to observe serving practices [16]. Prior to this phase there was prior notification to all licensees in the intervention area backed up by local media attention on the programme. Licensees were provided with a training video and table-top cards showing signs of intoxication and advice about legal penalties on serving staff and licensees for service to intoxicated patrons. Following the plain-clothes visits, feedback was given to licensees ranging from praise for good practice, through suggestions for improvement, to warnings and, ultimately, a fine. There were substantial increase in refusal of service to intoxicated patrons which was most pronounced when the programme was first launched and only warnings of pending enforcement were given: refusal rates increased to $54.3 \%$ of purchase attempts compared to only $16 \%$ following the earlier RBS training programme [13]. The evaluation also examined the incidence of alcohol-related road crashes involving people who had been drinking on licensed premises and found that these had sig- nificantly reduced following the introduction of the programme. It was estimated that for every dollar spent on this particular enforcement programme, between $\$ 90$ US and $\$ 280$ US was saved on the costs of road crashes.

A more direct and well-controlled comparison of training versus enforcement was reported by Grube [17] as part of the Community Trials Project, a large multi-site community intervention project to reduce alcohol-related harm conducted in California [18]. Grube reports on one specific focus of this major project-access to alcohol in liquor stores by under-age drinkers. In all over 479 liquor stores across 6 communities were included in the study. Three communities were intervention sites and three were control sites. The intervention sites received training of liquor store staff only, a police enforcement programme only or both interventions at the same time. The law enforcement intervention involved firstly letters advising owners of a new enforcement programme followed by a 'decoy' operation in which the police had under-age drinkers attempt to purchase alcohol. Stores selling to the decoys were fined. Prior to intervention approximately $50 \%$ of attempts by under-age drinkers to purchase alcohol were successful. There were significant reductions in proportions of stores willing to sell to under-age drinkers following the intervention, with rates of less than $20 \%$ where the police enforcement programme was used. The presence of training made no significant additional impact over and above the enforcement programme.

Taken together, these studies tell a similar and, perhaps, unsurprising story: a determined law enforcement approach in which penalties are applied to licensees breaking the law has a far more significant impact on the responsible service of alcohol at a community-wide level than does RBS training alone. It might seem that elaborate training programmes are unlikely to modify serving practices across many licensed premises and whole communities and that failure to adopt RBS practices is more a problem of motivation than of knowledge and skill.

Before RBS training is dismissed altogether as unnecessary, one interesting study with a more hopeful outcome should be mentioned. Holder \& Wagenaar [19] utilized 12 years of road-crash data for the entire United States to analyse the impact of the introduction of mandatory RBS training in the state of Oregon in 1986. The outcome measure was the surrogate measure of single-vehicle night-time crashes for alcohol-related crashes: these have been shown to 
involve prior consumption of alcohol in up to $80 \%$ of cases [20]. Despite the fact that the training was phased in over 2 years, there was an immediate and significant reduction in single-vehicle night-time crashes in Oregon compared with the rest of the United States after the law was passed. The reduction was sustained for the 18-month 'after' period of the study.

Why should the passing of a law requiring compulsory RBS training succeed where other largescale training programmes have failed? And why should the effect have been immediate? A plausible explanation is that law enforcement methods succeed to the extent that they deter law-breaking through publicizing the penalties. Homel [21] has described how deterrence operates in relation to the prevention of drinking and driving: an optimal outcome is not achieved be law enforcement alone unless it is highly visible and well-publicized. Thus random breathtesting is most effective when large, highly visible mobile testing units are employed backed-up with a vigorous media campaign. A related example in the liquor service area is the demonstration by Wagenaar $\&$ Holder [22] of reduced alcohol-related road crashes following highly publicized cases in which licensees have been sued successfully for millions of dollars when a drunk patron injures or kills a third party in a road crash.

In conclusion, in order to off-set the commercial imperative to sell alcohol to customers on demand, disincentives to serve alcohol to drunk and under-age customers can be created which are more effective than exhorting staff and managers to serve alcohol responsibly through the medium of RBS training. Such disincentives are most effective when they combine a targeted enforcement programme with general deterrence created by direct warnings and general publicity for the programme.

\section{Other law enforcement approaches focusing public order problems in and around licensed premises}

Two other approaches to law enforcement and licensed premises will be discussed: the use of uniformed patrols of premises at high risk times and the negotiation of local accords between police, licensees and a local community.

The classic study in the area of community policing of pubs was conducted by Jeffs \& Saunders [23] at a seaside resort in the south-west of England. During the summer months this resort was a popular destination for large groups of young people from other parts of the country and a public order problem was apparent around the local entertainment described, where there were many clubs and pubs. A community policing intervention was developed involving the used of uniformed police visiting all licensed premises in pairs two or three times per week. The officers on patrol would initiate friendly contact with the managers and be seen to make a thorough check for under-age and/or drunk customers. Jeffs \& Saunders (1983) report there was a 20\% reduction in public order offences which reverted to baseline when the intervention was discontinued. In addition there was no such reduction in a control town, which was also a seaside resort of similar size.

There have been a number of attempts to replicate the above studies, although few have been documented formally and published. One exception was a study reported by Burns et al. [24] in Sydney, Australia. In this exercise, uniformed police patrols visited licensed premises at high-risk times on over 1200 occasions in a popular entertainment area. Unlike the English study, no specific instructions were given to check for under-age or intoxicated customers. Rather, the philosophy appeared to be about preventing trouble-makers getting out of hand by creating a more visible police presence. At face value the results were disappointing. There was actually a significant increase in reported violent incidents although a slight decrease in local emergency department admissions in the intervention area. No measures of server behaviour or patron intoxication were employed.

These last findings are usefully seen in conjunction with a study conducted in Rhode Island, New York State, United States in which a broad-spectrum community intervention project to reduce alcoholrelated injuries included a liquor law enforcement component [25]. It was reported that arrests for assaults increased by $20 \%$ in the intervention site but that presentations of assault injuries to the local emergency room decreased by $25 \%$. These results are not as paradoxical as might first appear. It is well established that only a small proportion of assaults in public places are reported to the police [11]. An increased police presence inevitably creates more opportunities for such assaults to be observed and reported in official statistics. This need not be inconsistent in any way with an actual decline in alcohol-related violence as a consequence of the policing intervention. 


\section{Alcohol Accords}

In the 1990s a new model of regulating licensed premises emerged in Australia that came to be known the Accord. The idea emerged from the pioneering work of Ross Homel and colleagues [26] in the prime tourist area of Surfer's Paradise on the Queensland coast and also the earlier work of the West End Forum in Melbourne [27]. A project known as the Surfer's Safety Action Project was established in response to adverse media coverage of high rates of public drunkenness and alcohol-related violence concentrated in an entertainment area with over 20 nightclubs in close proximity to each other. A partnership was established between licensees, police, council officers and community representatives to create a safer environment and a less tarnished reputation for the area. A Code of Practice was drawn up and signed by all licensees to agree to limit high-risk promotional and sales practices such as discounting drinks, gimmicks to encourage fast or excessive intake and serving underage and intoxicated customers. Training of security staff to handle conflict by non-violent means and of bar staff in responsible service practices was also introduced, while licensees were encouraged to develop management policies to discourage intoxication and disorderly behaviour. Maintaining the agreement was in the commercial interests of participants, since the ban on discounting was in effect a pricefixing agreement. Venues that broke rank were 'grassed on' to a Best Practices committee oversighting the project and shamed into falling into line. An energetic evaluation team also closely monitored compliance and gave ongoing feedback to the committee. Within the first 6 months of the project there were significant improvements measured by a House Policy Checklist [28] in house policies and serving practices and a halving of violent incidents observed by researchers from 9.8 to 4.7 per 100 hours of observation. Unfortunately, at a 2-year follow-up this improvement had been lost and measures had returned to baseline.

The above approach has applied to innumerable local areas in Australia under the name of alcohol or licensing Accords. Two other evaluations have been conducted which have shown variously mixed [29] and weak outcomes [30]. It is evident that these Accords have taken different forms in different places according to local priorities but also the preparedness of police to tackle difficult issues such as service to intoxication. The evaluation of the Fremantle Accord found an increase in assault offences occurring in public places, which is likely to reflect the greater probability of detection afforded by a greater police presence as well as police sometimes being involved in assaults themselves [30]. The evaluation of the Geelong Accord in Victoria reported a halving of the rate of all assault offences but no control area was utilized and nor was any differentiation presented between assaults in public and private places, at daytime and night-time, in and around licensed premises or elsewhere and it is difficult to assess the claimed outcome [29]. An interesting feature of the Geelong Accord was the reported preparedness of the police to get tough on any non-compliant licensee by more regular visits and the issuing of fines for any observed minor infringement, e.g. not displaying the name of the licensee clearly at the entrance.

There can be no doubt that the Accord approach can be an effective harm-reduction strategy, at least in the short term and when there is an energetic monitoring presence. Interesting issues are raised regarding the legality of what are effectively pricefixing agreements. Another important issue is the extent to which the approach encourages or discourages police and licensing authorities to focus on the 'difficult' matters of service to intoxication and to under-age drinkers - or whether the alliance forged becomes a 'gentlemen's agreement' to turn a blind eye.

\section{Institutionalizing Responsible Beverage Service}

A number of potentially effective strategies have been described to encourage responsible service of alcohol on licensed premises and which have demonstrable impact on public health, safety and order outcomes. Failures of such strategies have occurred as a consequence of less than whole-hearted implementation or failure to sustain the effort of implementation over the longer term. Difficulties of recruiting police departments to participate in licensing law enforcement were described in the United States by McKnight; the Torquay policing experiment in England and Surfer's Paradise project in Australia demonstrated major short-term benefits in the reduction of alcohol-related violence; server training programmes in the United States and Australia were effective when management were totally supportive but the effectiveness was dissipated when training was provided to a wide cross-section of premises in a particular area. The energy to implement and sustain 
Table 1. Recommendations for institutionalizing RBS in legal, regulatory and socio-political structures

Legal structures

Well-drafted legislation with clear harm minimization objective

Mandatory server training

Banning of irresponsible promotions

Local controls over trading hours and conditions

Dram Shop Laws, i.e. laws which define legal responsibilities of licensees for behaviour of patrons after they leave the premises
Promoting supportive socio-political environment
Harm minimization as the major corporate goal of licensing authorities

Plain-clothes licensing inspectors

Uniformed police presence

Comprehensive training of licensing officers and police

Graded system of penalties leading

to temporary licence suspension
Public health advocacy on alcohol and licensing issues

Publicly disseminated data on harm and licensed premises Media campaigns promoting
licensing laws

Local licensing forums with community participation

Incentives for good practice by

licensees

such interventions can come from many sources: from the research community, from local community concerns, from rival licensees, from the police, from managers of venues and from adverse media coverage. How can all these forces be harnessed to avoid the situation that effective interventions are only introduced when things become very bad and when local community leaders are able to devote time and resources into implementing strategies that just happen to be effective? What can be done to sustain consistent and concerted prevention efforts? This discussion and review closes with a series of suggestions, summarized in Table 1, for institutionalizing RBS. These recommendations are made on the basis of both the author's interpretation of the available evaluation literature and of his experiences observing licensing and RBS interventions in practice.

It will be apparent that there are many players with an interest in how licensed premises perform and operate variously from the business community, government and non-government agencies. Community action projects frequently seek to achieve health and safety outcomes through negotiation, mutual agreement and co-operation. When such projects are evaluated against objective criteria and found to be wanting, there is an opportunity for community decision-makers to consider more formal changes in how local licensed premises are regulated and even whether local, state or provincial laws are in need of reform. Such was the experience of the Fremantle Respects You Project [14,28] when the steering committee was presented with hard data suggesting minimal impact of a server training programme and a series of recommendations for regulatory and legal reform. These recommendations were debated by the committee before the evaluation report was finalized. Since the membership included senior health, liquor licensing and police officials as well as the head of the state retailers' association, once agreement was reached and documented, an unstoppable momentum for law reform was created. While continued submissions and representations were required over almost 4 years, many significant reforms of the Western Australian Liquor Act were introduced by an amendment bill, several of which were first recommended by the consensus statement in the above evaluation report. For the first time there was a statement that a primary object of the Act was the minimization of alcoholrelated harm; a concise and useful definition of what constituted 'intoxication' was provided and the compulsory training of licensees and managers in RBS practices was introduced. Other strategies outside of 
the Act were also introduced such as the development of a host responsibility public education campaign to support licensees and party hosts in RBS. It should be stressed that these successes would not have occurred without energetic lobbying by the Alcohol Advisory Council of Western Australia throughout the legal review and amendment process.

A liquor licensing act which promotes RBS and empowers police, licensing authorities and local communities to take effective local action is one thing, but having that act utilized and enforced is quite another. Table 1 identifies the importance of having the corporate objectives of relevant authorities embracing the principles of RBS and having their staff thoroughly trained in a wide-range of community monitoring and enforcement strategies. It has been discussed in more detail elsewhere how regulatory structures can be created which are capable of effecting genuine deterrence against irresponsible promotions and management practices [e.g. 15,31]. For example, a graded system of penalties ranging from warnings, to modest fines, to temporary licence suspensions of differing lengths, to outright loss of licence is a highly desirable alternative to the situation in which the only available penalties are the laying criminal charges leading to large fines and loss of licence.

Even with a well-drafted liquor act with ample harm minimization provisions backed up by a wellorganized system of regulation may be inadequate if the host community is hostile or otherwise unsupportive. The support of the local community for such measures can never be taken for granted and a number of strategies are desirable to maintain a groundswell of support and an appropriate level of concern about the dangers of high-risk alcohol consumption. It is strongly recommended that local and regional alcohol advocacy groups are established to maintain publicity and a presence on alcohol prevention and policy with an emphasis on liquor licensing laws and their enforcement as a principal prevention 'lever' [7]. Another helpful strategy is to maintain a regular flow of data on local levels of alcohol related harm (or regional or national), ideally with details regarding harm associated with licensed premises, both in particular and in general. Such data should be made available to the general public when it is possible to do this and, of course, to local decision-makers within the legal and regulatory structures of liquor licensing. In addition, prevention activity on the ground is maximally effective when supported by relevant and hard- hitting media campaigns [e.g. 21]. All of these strategies can combine to create and maintain a social and political climate supportive of effective regulation and enforcement of liquor laws.

\section{References}

[1] Saltz R. The roles of bars and restaurants in preventing alcohol impaired driving: and evaluation of server intervention. Eval Health Profess 1987;10:5-27.

[2] Gliksman L, McKenzie D, Single E, Douglas R, Brunet S, Moffatt $\mathrm{K}$. The role of alcohol providers in prevention: an evaluation of a server intervention programme. Addiction 1993;88:1189-97.

[3] O'Donnell M. Research on drinking locations of alcohol-impaired drivers: implication for prevention policies. J Public Health Policy 1985;6:510-25.

[4] Solomon R, Prout L. Alcohol liability in Canada and Australia: sell, serve and be sued. Perth: National Centre for Research into the Prevention of Drug Abuse, Curtin University of Technology, 1996.

[5] Mosher JM. The impact of legal provisions on barroom behaviour: toward an alcohol problems prevention policy. Alcohol 1984;1:205-11.

[6] Lang E. Server intervention training: what chance in Australia? Drug Alcohol Rev 1991;10:381-93.

[7] Stockwell TR. Liquor outlets and prevention policy: the need for light in dark corners. Addiction 1997;92: 925-30.

[8] Roncek DW, Maier PA. Bars, blocks and crimes revisited: linking the theory of routine activities to the empiricism of 'Hot Spots'. Criminology 1991;29: $725-53$.

[9] Chikritzhs T, Stockwell TR, Masters L. Evaluation of the public health and safety impact of extended trading permits for Perth hotels and night-clubs. Perth: The National Centre for Research into the Prevention of Drug Abuse, Curtin University of Technology, 1997.

[10] Graham K, West P. Alcohol and crime, examining the link. In: Heather N. Stockwell T.R, Peters T, eds. Handbook of alcohol dependence and related problems. Sussex, UK: John Wiley and Sons, Ltd, 2001.

[11] Homel R, Tomsen S, Thommeny J. Public drinking and violence: not just an alcohol problem. J Drug Issues 1992;22:679-97.

[12] Russ NW, Geller ES. Training bar personnel to prevent drunken driving: a field evaluation. Am J Public Health 1987;77:952-4.

[13] McKnight AJ. Development and field test of a responsible alcohol service programme, final report Contract no. DTNH22-84-C-07170. Washington: National Highway Traffic Safety Administration, US Department of Transportation, 1988. 
[14] Lang E, Stockwell TR, Rydon P, Beel A. Can training bar staff in responsible serving practices reduce alcohol-related harm? Drug Alcohol Rev 1998;17: $39-50$.

[15] Rydon P, Stockwell TR. Local regulation and enforcement strategies for licensed premises. In: Plant M, Single E, eds. Alcohol: minimising the harm. London: Free Association Books, 1997.

[16] McKnight AJ, Streff FM. The effect of enforcement upon service of alcohol to intoxicated patrons of bars and restaurants. Accid Analysis Prev 1994;26: $79-88$.

[17] Grube JW. Preventing sales of alcohol to minors: results from a community trial. Addiction 1997;92: 251-60.

[18] Holder HD, Saltz RF, Grube JW, Voas RB, Gruenewald PJ, Treno AJ. A community prevention trial to reduce alcohol involved accidental injury and death: overview. Addiction 1997;92:155-71.

[19] Holder HD, Wagenaar AC. Mandated server training and reduced alcohol-involved traffic crashes: a time series analysis of the Oregon experience. Accid Anal Prev 1994;26:89-97.

[20] Zador PL, Lund AK, Fields M, Weinberg K. Fatal crash involvement and laws against alcohol-impaired driving. Washington, DC: Insurance Institute for Highway Safety, 1988.

[21] Homel R. Policing and punishing the drinking driver: a study of general and specific deterrence. New York: Springer-Verlag, 1988.

[22] Wagenaar AC, Holder HD. Effects of alcoholic beverage server liability on traffic crash injuries. Alcoholism: Clinical and Experimental Research, 1991(15): p. 942-947.

[23] Jeffs B, Saunders B. Minimising alcohol related offences by enforcement of the existing licensing legislation. Br J Addict 1983;78:67-78.

[24] Burns L, Flaherty B, Ireland S, Frances M. Policing pubs: what happens to crime? Drug Alcohol Rev 1995;14:369-76.

[25] Putnam SL, Rockett IR, Campbell MK. Methodological issues in community-based alcohol-related injury prevention projects: attribution of programme effects. In: Greenfield TK, Zimmerman R, eds. Experiences with community action projects: research in the prevention of alcohol and other drug problems. Rockville, Maryland: US Department of Health and Human Services, 1993.

[26] Homel R, McIlwain G, Carvolth. Creating safer drinking environments. In: Heather N, Stockwell TR, Peters T, eds. Handbook of alcohol dependence and related problems. Sussex, UK: John Wiley and Sons Ltd, 2001.

[27] Victorian Community Council Against Violence. Violence in and around licensed premises. Melbourne: Victorian Community Council Against Violence, 1990.

[28] Stockwell TR, Rydon P, Lang E, Beel A. An evaluation of the 'Freo Respects You' responsible alcohol service project. Perth: National Centre for Research into the Prevention of drug Abuse, Curtin University of Technology, 1993.

[29] Rumbold G, Malpass A, Lang E, Cvetkovski S, Kelly W. An evaluation of the Geelong Local Industry Accord: final report. Melbourne: Turning Point Alcohol and Drug Centre, 1998.

[30] Hawks D, Rydon P, Stockwell TR, White M, Chikritzhs T, Heale P. The evaluation of the Fremantle Police Licensee Accord: impact on servicing practices, harm and the wider community. Perth: National Drug Research Institute, Curtin University of Technology, 1999.

[31] Stockwell TR. Alcohol misuse and violence: an evaluation of the appropriateness and efficacy of liquor licensing laws across Australia, report no. 5. Canberra: Australian Government Publishing Service, 1995. 